\title{
What Is It About This Substance?
}

\author{
Andrew J. McLean ${ }^{1}$ \\ Received: 19 April 2017 / Accepted: 8 June 2017 / Published online: 21 July 2017 \\ (C) Academic Psychiatry 2017
}

\section{Artist's Statement}

This poem is a reminder of the individual's experience in addiction, the acknowledgment of pain to self and others, the wish to change, and the powerlessness that can occur. Substance use disorders are ubiquitous in our field, and the reader may see a patient, a friend, a family member, or themselves in this poem. Our community recently lost a medical practitioner who, while in recovery, developed a chemical dependency treatment program which significantly helped educate our medical students and residents. This poem is dedicated to him.
Andrew J. McLean

andrew.mclean@med.und.edu

1 UND School of Medicine and Health Sciences, Fargo, ND, USA
What Is It About This Substance?

What is it about this substance

That causes me to abandon everything?

To suffer existential myopia;

To reduce salience to the size and weight

Of a singularity

As family and friends orbit

Like desperate moons,

Avoiding the event horizon

That is my addiction.

What is it about me, and not

My friends or siblings that

Allows for this condition?

Bad luck? Step on a crack?

Piss off the Devil (or God)?

This drug affects my life

By month, week, day;

By second.

It is not in my true nature

To behave this way-to talk

This way.

Compassion gives way to sociopathy,

Eloquence to profanity.

I stumble in the shadowy jungle

Addiction

Where the wild beast Substance

Has grabbed me by the throat

And won't let go. 